\title{
Children Obesity
}

\author{
Frida Gómez Mendoza* \\ Department of Pediatric Nutrition, University of Iberoamerican, Mexico, Mexico \\ *Corresponding author: Frida Gómez Mendoza, Department of Pediatric Nutrition, University of Iberoamerican, Federico Gómez \\ Children's Hospital of México, CP 06720 Mexico City.
}

To Cite This Article: Frida Gómez Mendoza. Children Obesity. Am J Biomed Sci \& Res. 2021 - 13(3). AJBSR.MS.ID.001871. DOI: 10.34297/AJBSR.2021.13.001871.

Received: 非 June 24, 2021; Published: 非 June 28, 2021

\section{Opinion}

Childhood obesity is one the most serious health problem of the 21st century. The prevalence has increase and it is alarming. In 2016, the number of overweight children in the age of five years, is estimated to be over 41 million [1]. Obesity is defined as a body mass index (BMI) at above 95 percentiles for children and the same age and sex. A children weight status is determinate using age and sex because of children's body composition varies as the age and varies between boys and girls [2]. It is important to talk about the children obesity because it is a disease that can be stop and the kids have better life and health also in the future. Obese children are more likely to become adults with obesity. Obesity in children may result from high sugar intake, longer screen time, and sedentary lifestyle.

Sugar is present naturally in different food that contain carbohydrates, like for example: fruit and grain. The good form it is to eat all the food in balance. However, the problem become when children consume too much added sugar, that is, sugar that food manufactured add to products to increase de flavor [3]. High sugar intake impact in obesity and diabetes. Children are consumed sugar as a part of them diet. It is important mention that sugar is not a required nutrient in children diet. Sugar makes us no longer hungry but when we been hungry, we prefer to eat sugar. Children aged 3-10 years should take more than 6 sugar cubes ( $25 \mathrm{~g}$ ) at day, when children only can take $3 \mathrm{~g}$ [4]. That it is one of the reason of children obesity the high sugar intake. However, this is not the only cause of children obesity.

Screen time is a term use for activities in front of a screen, as follow: TV, computer, cellphones, and video games [5]. Screen time is a sedentary activity that means you are being physically inactive, in as much as, children spend time sitting. Children spend about 3 hours day watching TV. Further, all types of screen time can total 7 hours a day [5]. Screen time is linked to childhood obesity and increase child's risk for obesity, on account of, sitting and watching screen time results in physical inactivity. TV commercial can lead to unhealthy food choices, these foods are hight in sugar, fat, and sodium. In the other hand, children eat more when they are watching TV and they choices hypercaloric food [6].

Sedentary lifestyle is type of style involving little or no physical activity, sedentary behavior is not the same as physical inactivity; sedentary behavior refers to low-energy pursuits such as television viewing, reading, and activities when the children do not move. Of all measures of sedentary lifestyle, only screen time has a known positive association with increased adiposity, children who spend more than 2 hours of daily screen time were 1.8 times more likely to be obese or overweight (Barnnet, et al. 2018). Nowadays children are usually sedentary since their parents work and the children are left alone. Moreover, children do not have extra classes for example play football or do a physical activity resulting in being obese or overweight.

Childhood obesity is a problem worldwide, and the reasons are multiple. Still, sugar consumption, screen hours and sedentary lifestyle are red flags for the increase in obesity.

To sum up, obesity in children may result from high sugar intake, longer screen time, and sedentary lifestyle. A child with obesity has many health problems. Childhood obesity is a disease that, if not controlled, has consequences in adult life. The best way to prevent childhood obesity is to have a good diet that includes carbohydrates, proteins, and lipids, in addition to do physical activity and limiting screen time to two hours per day. 


\section{References}

1. (2016) Childhood overweight and obesity. World Health Organization.

2. (2018) Defining Childhood Obesity. CDC.

3. (2017) The sweet danger of sugar. Harvard Medical School.

4. (2020) Sugar: the facts. NHS.
5. Strasburger VC, Jordan AB, Donnerstein E (2010) Health effects of media on children and adolescents. Pediatrics 125(4): 756-767.

6. Gahagan S (2020) Overweight and obesity. In: Kliegman RM, St. Geme JW, Blum NJ, Shah SS, Tasker RC, Wilson KM, eds. Nelson Textbook of Pediatrics. (21st Ed.) Elsevier chap 60. 